\title{
Distribution Network Voltage Control Based on Coordinated Optimization of PV and Air-Conditioning
}

\author{
Qi Wang $\mathbb{D}^{1,2}$ Bin Lu, ${ }^{1,2}$ Xiaobo Dou $\mathbb{D}^{3}{ }^{3}$ Yichao Sun, ${ }^{1,2}$ and Jin Liu ${ }^{1,2}$ \\ ${ }^{1}$ School of Electrical \& Automation Engineering, Nanjing Normal University, Nanjing 210042, China \\ ${ }^{2}$ Jiangsu Province Gas-electricity Integrated Energy Engineering Laboratory, Nanjing 210046, China \\ ${ }^{3}$ School of Electrical Engineering, Southeast University, Nanjing 210096, China
}

Correspondence should be addressed to Qi Wang; wangqi@njnu.edu.cn

Received 8 February 2018; Accepted 22 April 2018; Published 3 June 2018

Academic Editor: Mahmoud M. El-Nahass

Copyright ( 2018 Qi Wang et al. This is an open access article distributed under the Creative Commons Attribution License, which permits unrestricted use, distribution, and reproduction in any medium, provided the original work is properly cited.

This paper proposes a coordinated optimal control strategy of PV generators and air-conditioning loads, in order to handle the possible voltage beyond limit issues resulting from high penetration of PV generators in the distribution networks. This strategy is achieved via coordinately considering the node voltage sensitivity and the adjustment-compensation bid model, to improve the economy of the whole system. As a result, the shortage of the PVs' reactive power control capability is compensated by the adjustable air-conditioning loads, so that the waste of the photovoltaic power can be reduced or even avoided. The case study using an IEEE standard 33-node system, which is further updated with the installation of 5 PV generators and 5 air-conditioning loads, validates the correctness and effectiveness of the proposed control strategy.

\section{Introduction}

As the problem of energy shortage and environmental pollution is more critical, access of a distributed generator (DG) such as PV and wind power to the distribution network has become an important trend of distribution network development. Distributed PV access to the distribution network can realize the local balance of energy, cut the investment, and reduce the loss of long-distance power transmission. At the same time, making use of clean and renewable PV power can replace traditional fossil energy and improve energy structure. Due to the randomness and volatility of the PV power, a large number of distributed PV access also bring power quality problems, such as voltage fluctuation and flicker and voltage off-limit to the power grid [1], which endanger the safe and stable operation of the power grid.

The problem of voltage off-limit has become one of the main factors restricting the scale and permeability of distributed PV power in the distributed network [2]. When the PV output is high and the load is light, it may easily cause the problem of voltage off-limit [3]. Traditional solutions are generally focused on the supply side, and the main solutions are adjusting the reactive power of the PV inverter [4], installing reactive-load compensation equipment such as a reactor [5], and calling energy storage equipment to absorb the extra PV power $[6,7]$. If necessary, the measure of removing part of active power, namely, "waste of PV power," must be taken [8].

During the scheme above, due to the limit of the power factor, adjusting the reactive power of the inverter has limited effect on voltage adjustment, and the installing of reactive compensation equipment and energy storage equipment brings additional investment. The "waste of PV power" reduces the utilization of renewable energy. If the voltage can be ensured under the limit and the economy can be improved at the same time, it will promote the scale and permeability of distributed PV in the distribution network.

With the deeper research of smart grid and demandside response, more and more researchers begin to pay attention to the great potential of flexible loads such as air-conditioning in power system regulation [9]. At present, relevant researches mainly focus on the establishment of 
an air-conditioning load model [10], the prediction of airconditioning load [11], and air-conditioning load participating in peak load regulation and frequency modulation $[10,12]$. If the regulation ability of an air-conditioning load can be used, though increasing air-conditioning power to consume the excessive PV power, it will be able to make up for the inadequacy of photovoltaic reactive power regulation ability and at the same time reduce the waste of PV power and the investment of energy storage and reactive compensation equipment, which provides a new method to solve the problem of voltage off-limit.

This paper considers the regulation potential of the air-conditioning load which coordinates with the voltage adjustment ability of PV itself and puts forward a voltage control strategy for the distribution network of coordinated optimization of photovoltaic and air-conditioning loads. In the distribution network, when voltage exceeds the limit due to the excess photovoltaic output, based on the voltage sensitivity and the pricing model of photovoltaic and air conditioner, the PV reactive power, air-conditioning load and PV active power regulation is allocated, so that the voltage limit control can be realized at the lowest amount of compensation. At the same time, this strategy maximizes the amount of photovoltaic power generation. On the other hand, the air conditioner user gets the compensation during the regulation, and after the adjustment, it can also maintain indoor temperature at a relatively low power. This strategy takes into account the benefits of the photovoltaic, air conditioner, and power grid side, which has high economic efficiency.

\section{The Pricing Model of PV and Air-Conditioning}

2.1. Adjustment-Compensation Bid Model of PVs. When using the reactive voltage regulation capability of $\mathrm{PV}$, the maintenance cost should be taken into consideration:

$$
c_{\mathrm{pv}, \mathrm{q}}=c_{\mathrm{q}},
$$

where $c_{\mathrm{pv}, \mathrm{q}}$ is the compensation price for the reactive power adjustment of PV and $c_{\mathrm{q}}$ is the maintenance cost of $\mathrm{PV}$ adjusting reactive power.

When using the active voltage regulation capability of $\mathrm{PV}$, the maintenance cost and the loss of power should be taken into consideration:

$$
c_{\mathrm{pv}, \mathrm{p}, i}=c+c_{\mathrm{p}}+k_{\mathrm{pv}} P_{\mathrm{pv}}
$$

where $c_{\mathrm{pv}, \mathrm{p}}$ is the compensation price for the active power adjustment of PV; $c$ is the selling price of electricity, $c_{\mathrm{p}}$ is the maintenance cost of $\mathrm{PV}$ adjusting active power; $k_{\mathrm{pv}}$ is the user preference coefficient, which is determined by each user; and $P_{\mathrm{pv}}$ is the amount of active power adjustment.

2.2. Adjustment-Compensation Bid Model of Air-Conditioning Loads. In this paper, the adjustment-compensation bid model of air-conditioning loads is formulated by the

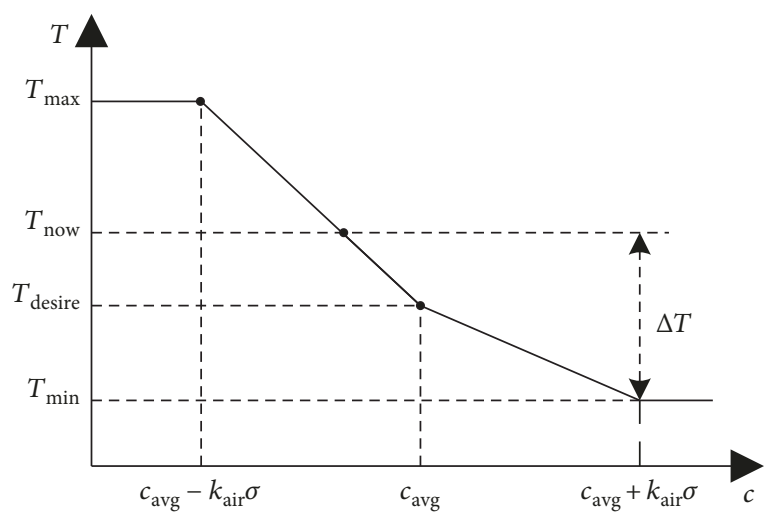

FIgURE 1: The air-conditioning curve of cost and temperature.

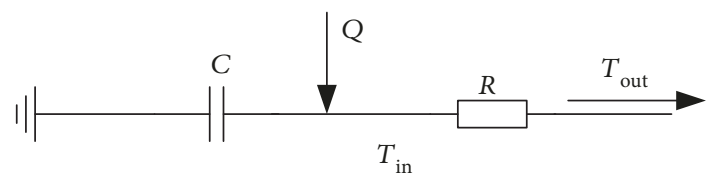

FIgURE 2: Equivalent thermal parameter model of air-conditioning.

following steps: first, users define their temperaturecompensation model based on their choices between comfort and earning. Then the adjustment-compensation model is formulated by combining the temperature-compensation model and the thermodynamic model of the building where the air-conditioning is located.

2.2.1. Temperature-Compensation Model. The temperaturecompensation model is shown in Figure 1, where $T_{\max }$, $T_{\text {min }}$, and $T_{\text {desire }}$ are user-specified maximum, minimum, and desired indoor temperatures, respectively; $c_{\text {avg }}$ is the average compensation price of a certain price history; $\sigma$ is the standard variation of the compensation prices during the given history; $k_{\mathrm{air}}$ is the user preference coefficient, which is determined by each user; and the $\Delta T$ part in Figure 1 shows the adjustable range [13].

The curve in Figure 1 can be expressed as the following piecewise function:

$$
T= \begin{cases}T_{\max }, & c_{\text {air }} \leq c_{\text {avg }}-k_{\text {air }} \sigma, \\ k_{1} c_{\text {air }}+b_{1}, & c_{\text {avg }}-k_{\text {air }} \sigma<c_{\text {air }} \leq c_{\text {avg }}, \\ k_{2} c_{\text {air }}+b_{2}, & c_{\text {avg }}<c_{\text {air }} \leq c_{\text {avg }}+k_{\text {air }} \sigma, \\ T_{\text {min }}, & c_{\text {air }}>c_{\text {avg }}+k_{\text {air }} \sigma,\end{cases}
$$

where $c_{\text {air }}$ is the compensation price for air-conditioning and $k_{1}, k_{2}, b_{1}$, and $b_{2}$ are coefficients.

2.2.2. Thermodynamic Model of the Building Where the AirConditioning Is Located. In this paper, the equivalent thermal parameter (ETP) model is used in the thermodynamic model of the building where the air-conditioning is located, which is shown in Figure 2 [14]. 
The ETP model has the following expression:

$$
\begin{aligned}
T_{\text {in }, t+1}= & \text { coe } \cdot T_{\text {in }, t}+(1-\text { coe }) T_{\text {out }, t} \\
& +\operatorname{COP} \cdot R \cdot(1-\operatorname{coe}) \cdot P_{\text {air }}, \\
\text { coe }= & e^{-\Delta t / R C}
\end{aligned}
$$

where $C$ is the equivalent heat capacity, $R$ is the equivalent heat resistance, $T_{\text {out }, t}$ is the outside temperature at $t$ time, $T_{\text {in, } t}$ is the indoor temperature at $t$ time, $P_{\text {air }}$ is the average power from $t$ time to $t+1$ time, COP is the energy efficiency, and $\Delta t$ is the time interval.

By combining (3) with (4) and (5), the adjustmentcompensation model is finally formulated with the following expression:

$$
P_{\mathrm{air}}= \begin{cases}\frac{P_{\mathrm{min}},}{k_{1} c_{\mathrm{air}}+b_{1}-e^{-\Delta t / R C} \cdot T_{\mathrm{now}}-\left(1-e^{-\Delta t / R C}\right) T_{\mathrm{out}, t},} & c_{\mathrm{air}} \leq c_{\mathrm{avg}}-k_{\mathrm{air}} \sigma, \\ \frac{k_{2} c_{\mathrm{air}}+b_{2}-e^{-\Delta t / R C} \cdot T_{\mathrm{now}}-\left(1-e^{-\Delta t / R C}\right) T_{\mathrm{out}, t}}{R\left(1-e^{-\Delta t / R C}\right) \mathrm{COP}}, & c_{\mathrm{avg}}<c_{\mathrm{air}} \leq c_{\mathrm{avg}}+k_{\mathrm{air}} \sigma \\ P_{\mathrm{max}}, & c_{\mathrm{air}}>c_{\mathrm{avg}}+k_{\mathrm{air}} \sigma,\end{cases}
$$

where $P_{\min }$ is the minimum air-conditioning power, which is equal to the larger value between 0 and air-conditioning power when $T=T_{\max }$, and $P_{\max }$ is the maximum airconditioning power, which is equal to the smaller value between the rated power and the power when $T=T_{\min }$.

\section{Coordinate Optimization Control Strategy of PV and Air-Conditioning Load}

3.1. Overall Framework. Figure 3 shows the coordinative optimization control strategy of photovoltaic and airconditioning load. When the distribution network exists at the voltage limit, voltage-centralized controllers make a power flow calculation online in the distribution network. Based on the Jacobi matrix, this paper deduces the active and reactive power sensitivities of all nodes related to $\mathrm{PV}$ or air-conditioning. Meanwhile, each PV and air-conditioning submits its own adjustment quantity-compensation price model. After sensitivities and adjustment, a quantitycompensation price model is built; the target is to minimize the total compensation. The objective function is established by considering constraints which relate to voltage overlimit elimination, power limit at each node, and users' comfort index. The objective function is resolved to optimize the adjustment of each PV and air-conditioning. Each PV and air-conditioning gains access to the regulation information. According to the adjustment, each PV and air conditioner adjusts its own output to solve the voltage overlimit problem.

3.2. Objective Function. For nodes where PV and airconditioning are installed, the target is to determine the minimum compensation payment of regulation in the distribution network, namely,

$$
\begin{aligned}
& F\left(P_{\mathrm{pv}, 1}, \ldots, P_{\mathrm{pv}, N_{\mathrm{pv}}}, Q_{\mathrm{pv}, 1}, \ldots, Q_{\mathrm{pv}, N_{\mathrm{pv}}}, P_{\mathrm{air}, 1}, \ldots, P_{\mathrm{air}, N_{\mathrm{air}}}\right) \\
& =\min \left[\left(\sum_{i=1}^{N_{\mathrm{pv}}}\left(c_{\mathrm{pv}, \mathrm{p}, i} P_{\mathrm{pv}, i}+c_{\mathrm{pv}, \mathrm{q}, i} Q_{\mathrm{pv}, i}\right)+\sum_{j=1}^{N_{\mathrm{arr}}} c_{\mathrm{air}, j} P_{\mathrm{air}, j}\right) \Delta t\right],
\end{aligned}
$$

where $N_{\mathrm{pv}}$ and $N_{\text {air }}$ are the quantities of PV and air-conditioning, respectively, which are involved in the regulation; $c_{\mathrm{pv}, \mathrm{p}, i}$ and $c_{\mathrm{pv}, \mathrm{q}, i}$ are the compensation price of active and reactive regulations, respectively, of the $i$ th $\mathrm{PV}$; and $P_{\mathrm{pv}, i}$ and $Q_{\mathrm{pv}, i}$ are the active and reactive regulations, respectively, of the $i$ th PV. $P_{\mathrm{air}, j}$ is the power regulation of the $j$ th air-conditioning, and $c_{\text {air, } j}$ is the compensation price of the $i$ th air-conditioning.

3.3. Constraints. On the basis of the objective function, the constraints which need to be satisfied are as follows.

3.3.1. Constraint of the Elimination of Voltage Violation. The elimination of voltage violation can be determined as follows:

$$
\left|\Delta U_{n}-\left(\sum_{i=1}^{N_{\mathrm{p}}} j_{\mathrm{p}, i, n} P_{i}+\sum_{k=1}^{N_{\mathrm{q}}} j_{\mathrm{q}, k, n} Q_{k}\right)\right| \leq \alpha, \quad n=(1,2, \ldots, N),
$$

where $\Delta U_{n}$ is the difference between voltage at the $n$th node and 1.0 p.u.; $N$ is the number of nodes in the distribution network; $N_{\mathrm{p}}$ and $N_{\mathrm{q}}$ are the nodes involved in active and reactive power regulations, respectively; $j_{\mathrm{p}, i, n}$ is the active sensitivity of the $i$ th node related to the $n$th node; $j_{\mathrm{q}, k, n}$ is the reactive sensitivity of the $k$ th node related to the nth node; $P_{i}$ is the active regulation of the $i$ th node; $Q_{k}$ is the reactive regulation of the $k$ th node; and $\alpha$ is the maximum voltage deviation allowed during voltage controlling, which can be 


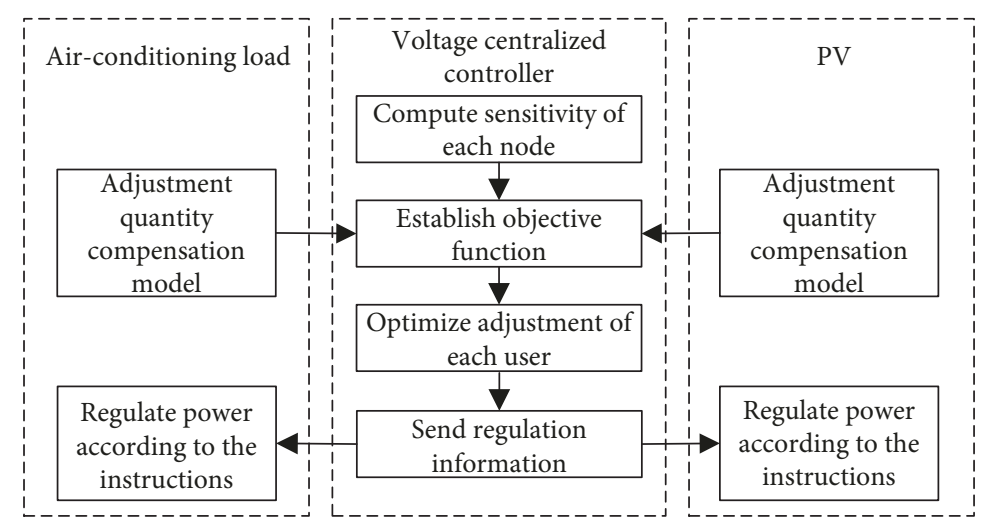

Figure 3: Coordinated optimal control structure of PV and air-conditioning.

determined according to the actual voltage level and voltage regulation requirements. This constraint means that the voltage is within the range of $1-\alpha$ p.u. to $1+\alpha$ p.u. after regulation.

3.3.2. Upper Bound of Power Regulation. For each PV generation, we have

$$
\begin{aligned}
P_{\mathrm{pv}, i} & \leq P_{\mathrm{pv}, \max }, \\
Q_{\mathrm{pv}, i} & \leq Q_{\mathrm{pv}, \max }, \\
P_{\mathrm{pv}, i}^{2}+Q_{\mathrm{pv}, i}^{2} & \leq S_{\mathrm{pv}, i}^{2}, \\
\cos \varphi_{i} & \leq 0.98 .
\end{aligned}
$$

Namely, solar power should not only meet the upper bound of the active and reactive power output but also meet the constraint of the power factor.

For each air-conditioning load, we have

$$
P_{\mathrm{air}, i} \leq P_{\mathrm{air}, \max },
$$

which means that air-conditioning only needs to meet the upper bound of the active power.

3.3.3. Constraint of Users' Comfort. For each air-conditioning load, it should also be that in the regulation process, the indoor temperature does not exceed upper and lower temperature limits that are defined by the users. Accordingly, we have

$$
T_{\min } \leq T_{\mathrm{in}, t+1} \leq T_{\max } .
$$

\section{Case Study}

In order to verify the effectiveness of the proposed strategy, this section makes a simulation analysis under the IEEE 33-node distribution system, as shown in Figure 4.

The 33-node test system was built in the DigSILENT/ PowerFactory simulation platform; 5 nodes are chosen from the 33 nodes to install photovoltaic panels and another 5 nodes are placed with air-conditioning loads. The user type and voltage sensitivity of each node are shown in Table 1. Assume that the outdoor temperature is $34^{\circ} \mathrm{C}$ and the indoor temperature is $26^{\circ} \mathrm{C}$. The maximum temperature, minimum

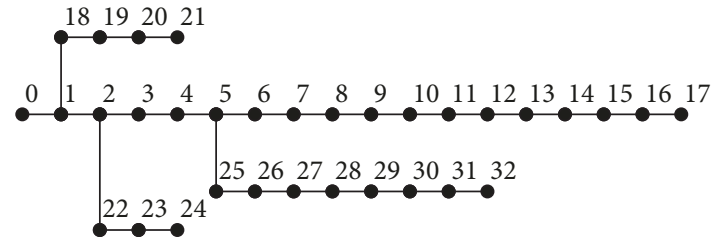

FIGURE 4: IEEE 33-node test system.

TABLE 1: The user type and voltage sensitivity of each node.

\begin{tabular}{lccc}
\hline $\begin{array}{l}\text { Node } \\
\text { number }\end{array}$ & User type & $\begin{array}{l}\text { Installed } \\
\text { capacity }\end{array}$ & $\begin{array}{c}\text { Voltage sensitivity } \\
\text { (p.u./MW (Mvar) })\end{array}$ \\
\hline 7 & PV & 1 MVA & $\begin{array}{c}\text { Active: } 0.014041 \\
\text { Reactive: } 0.015123\end{array}$ \\
11 & PV & 2 MVA & $\begin{array}{c}\text { Active: } 0.027051 \\
\text { Reactive: } 0.025023\end{array}$ \\
17 & PV & 2 MVA & $\begin{array}{c}\text { Active: } 0.053279 \\
\text { Reactive: } 0.054883\end{array}$ \\
19 & PV & $1.5 \mathrm{MVA}$ & Active: 0.000424 \\
32 & PV & $2 \mathrm{MVA}$ & Active: 0.010038 \\
8 & Air-conditioning & $1 \mathrm{MW}$ & Reactive: 0.009773 \\
13 & Air-conditioning & $1 \mathrm{MW}$ & Active: 0.019006 \\
15 & Air-conditioning & 0.037459 \\
20 & Air-conditioning & $1 \mathrm{MW}$ & Active: 0.044487 \\
31 & Air-conditioning & $1 \mathrm{MW}$ & Active: 0.000424 \\
\hline
\end{tabular}

temperature, and expected temperature designated by airconditioning users are $26^{\circ} \mathrm{C}, 18^{\circ} \mathrm{C}$, and $22^{\circ} \mathrm{C}$, respectively. The air-conditioning load of each node is initially operated with a minimum power to maintain the room temperature not more than $26^{\circ} \mathrm{C}$. The air-conditioning user benefit coefficient $k_{\text {air }}=2$, the PV panel user benefit coefficient $k_{\mathrm{pv}}=0.001$, and the maximum of permissible voltage deviation $\alpha=0.03$ p.u. The operating and maintaining costs of the PV active power and reactive power adjustment are $\$ 0.0008$ per $\mathrm{kW} \cdot \mathrm{h}$ and $\$ 0.0014$ per kvar.h, respectively [15]. 


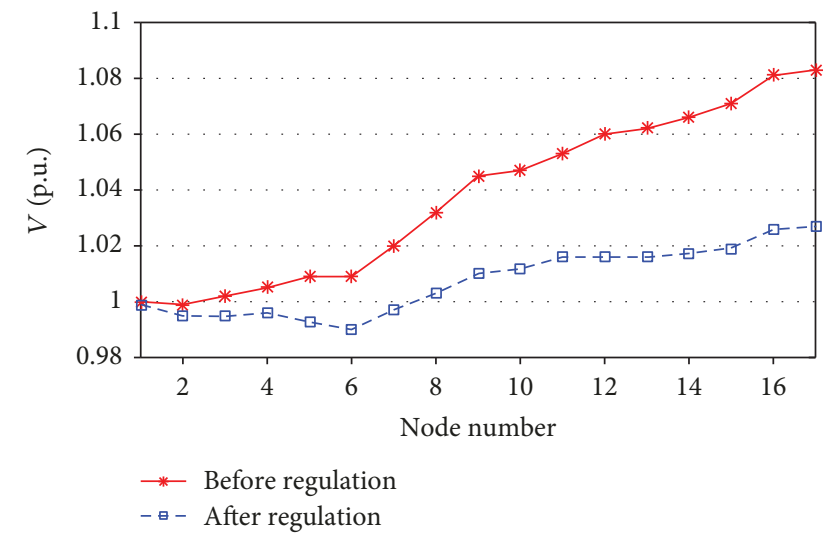

Figure 5: The voltage of each node in the main feeder.

Taking some node voltage of the 33-node main feeder is overlimited as a consequence of the excess of photovoltaic power at some time. Since the main feeder is a chain structure, making reactive power compensation at the end of the feeder is the most effective [16]. Therefore, considering voltage sensitivities of the nodes where the PV and air conditioners are located at the number 17 node at the end of the main feeder, this section analyzes the optimal results. Through online power flow calculation, the voltage sensitivities mentioned above can be achieved. The calculation result is shown in Table 1.

4.1. Result of Control of Voltage beyond Limits. We adopt the control strategy proposed in this paper and use the voltage regulating equipment at each node to adjust the main feeder voltage. A comparison of the raw and the adjusted voltage is shown in Figure 4.

Due to the excess of photovoltaic power, without adopting the proposed strategy, voltage goes beyond the limit at nodes 11-17 in Figure 5. The voltage limit violation is the most serious at the number 17 node, where the voltage has approached 1.083 p.u. That is why we need to take drastic measures to ensure that the voltage at each node of the distribution network meets the operational requirements. In the strategy adopted, the voltage at each node is regulated within an allowable range of 0.97 p.u. to 1.03 p.u., where voltage overlimit constraints can be eliminated.

The amount of power adjustment of each user is shown in Table 2. Voltage sensitivity of the number 7, number 11, number 17 , and number 32 nodes is high. And the PV reactive power output of these four nodes reached the upper limit of the reactive power output limited with the power factor constraints. For the sake of lower voltage sensitivity, the 19th node has pool regulation effects and will not be involved in the voltage regulation. The active power sensitivity of the 15 th node is the most visible. The remaining power is assumed by increasing the output of the air-conditioning at the 15 th node to meet the regulatory requirement. As a result, the rest of the air-conditioning was loaded only with the minimum power to maintain the indoor temperature to meet user comfort constraints, being unnecessary in participating in the regulation. Besides, PV panels can maintain the
TABLE 2: The amount of adjustment of each user.

\begin{tabular}{lccc}
\hline $\begin{array}{l}\text { Node } \\
\text { number }\end{array}$ & User type & $\begin{array}{c}\text { Active power } \\
\text { regulation }(\mathrm{kW})\end{array}$ & $\begin{array}{c}\text { Reactive power } \\
\text { regulation (kvar) }\end{array}$ \\
\hline 7 & PV & 0 & 101.5295 \\
11 & PV & 0 & 304.5885 \\
17 & PV & 0 & 203.0590 \\
19 & PV & 0 & 0 \\
32 & PV & 0 & 304.5885 \\
8 & Air-conditioning & 0 & - \\
13 & Air-conditioning & 0 & - \\
15 & Air-conditioning & 565.15 & - \\
20 & Air-conditioning & 0 & - \\
31 & Air-conditioning & 0 & \\
\hline
\end{tabular}

TABLE 3: The compensation price for participants in the regulation.

\begin{tabular}{lc}
\hline Node number & Compensation price \\
\hline 7 & $\$ 0.0014 / \mathrm{kvar} \cdot \mathrm{h}$ \\
11 & $\$ 0.0014 / \mathrm{kvar} \cdot \mathrm{h}$ \\
17 & $\$ 0.0014 / \mathrm{kvar} \cdot \mathrm{h}$ \\
32 & $\$ 0.0014 / \mathrm{kvar} \cdot \mathrm{h}$ \\
15 & $\$ 0.0487 / \mathrm{kW} \cdot \mathrm{h}$ \\
\hline
\end{tabular}

current generation power instead of curtailing PV power to control voltage.

In summary, the proposed strategy can not only solve the problem of distribution network voltage beyond the limit but also avoid the curtailment of PV power.

4.2. Economic Analysis. The compensation price for participants in the regulation is shown in Table 3.

The duration time of regulation is $5 \mathrm{~min}$. We figure out that the cost of the compensation is \$2.3538. Making full use of the reactive power regulation, the cost of which is low, minimizes the use of PV power curtailment which is expensive. Thus, this strategy can reach the minimum cost of compensation paid by the grid. Minimizing the use of PV power curtailment achieves the PV power accommodation maximization.

When the regulation ends, the air-conditioning load of the number 15 node involved in this regulation turns off and the room temperature recovers naturally. According to (4) and (5), it takes $10 \mathrm{~min}$ to recover from room temperature to $26^{\circ} \mathrm{C}$. In order to highlight the effect of the control strategy, the following 2 control schemes are used for comparison. In case 1 , we adopt the strategy proposed in this paper. In case 2, without using the proposed strategy, we maintain the room temperature at $26^{\circ} \mathrm{C}$. Considering the payment of electricity and the variation of temperature, we compare case 1 with case 2 . The electricity price is $\$ 0.0783 / \mathrm{kW} \cdot \mathrm{h}$ which is an experienced value based on the electricity price in China.

As is shown in Table 4, even if the air-conditioning is turned off when the regulation ends, the temperature in the room will not rise quickly in a short period of time. It is because the buildings can store heat. The consumption is 
TABLE 4: Economic comparison of air-conditioning in different participation cases.

\begin{tabular}{lcc}
\hline Contrast terms & $\begin{array}{c}\text { Under } \\
\text { regulation }\end{array}$ & $\begin{array}{c}\text { Without } \\
\text { regulation }\end{array}$ \\
\hline Temperature at the beginning & $26^{\circ} \mathrm{C}$ & $26^{\circ} \mathrm{C}$ \\
Temperature at the end & $25.77^{\circ} \mathrm{C}$ & $26^{\circ} \mathrm{C}$ \\
Temperature 10 min later & $26.01^{\circ} \mathrm{C}$ & $26^{\circ} \mathrm{C}$ \\
after regulation & $72.20 \mathrm{~kW} \cdot \mathrm{h}$ & $73.52 \mathrm{~kW} \cdot \mathrm{h}$ \\
Total electricity consumption & $\$ 2.33$ & $\$ 0$ \\
Compensation gained & $\$ 3.37$ & $\$ 5.86$ \\
Actual electricity payment & & \\
\hline
\end{tabular}

very low for the duration. Therefore, the total electricity consumption is maintained regardless of the increase in temporary consumption. Besides, users participating in the regulation can gain compensation from the grid company, so the users actually can reduce the electricity payment. It can be seen that the regulation and control proposed will not cause any damage to users' economic interests.

To summarize, the proposed strategy can effectively solve the voltage beyond the limit and has high economic efficiency.

\section{Conclusions}

This paper presents a distribution network voltage control strategy based on the coordinated optimization of PV and air-conditioning. The result of the case study shows that the strategy can optimize and allocate the adjustment amount of each PV and air-conditioning according to the sensitivity and the adjustment-compensation bid models. Users who are located in highly sensitive nodes and have lower compensation price participate in the arrangement preferentially, so that the grid can take the optimal control effect with the lowest payment. The adjustment-compensation bid models are submitted by PV and air-conditioning users themselves, which ensures the interest of each user. In addition, airconditioning users can keep the indoor temperature with lower power after the arrangement, and the waste of the photovoltaic power can be reduced or even avoided. The investment of reactive compensation equipment can be saved to a certain degree as well. As a result, the benefits of all the PV generators, the air-conditioning loads, and the grid are guaranteed.

The presented strategy can be promoted to the coordinated optimization of different kinds of loads and power sources to solve problems like voltage drop caused by the loss of active power. This makes contributions to restraining the fluctuation of renewable power and improving the penetration of distributed generations.

Considering that the output of PV and air-conditioning is time-variant, models reflecting the impact of response characteristics accurately and strategies based on the output characteristics of different loads and generators deserve further research.

\section{Data Availability}

The data used to support the findings of this study are available from the corresponding author upon request.

\section{Conflicts of Interest}

The authors declare that there is no conflict of interest regarding the publication of this paper.

\section{References}

[1] C. H. Wei, A. I. Xin, W. U. Tao, and L. Hui, "Influence of gridconnected photovoltaic system on power network," Electric Power Automation Equipment, vol. 33, no. 2, pp. 26-32, 2013.

[2] R. Yan and T. K. Saha, "Investigation of voltage stability for residential customers due to high photovoltaic penetrations," IEEE Transactions on Power Systems, vol. 27, no. 2, pp. 651662, 2012.

[3] R. A. Shayani and M. A. G. de Oliveira, "Photovoltaic generation penetration limits in radial distribution systems," IEEE Transactions on Power Systems, vol. 26, no. 3, pp. 1625-1631, 2011.

[4] Y. Wang, F. Wen, B. Zhao, and X. Zhang, "Analysis and countermeasures of voltage violation problems caused by high-density distributed photovoltaics," Proceedings of the CSEE, vol. 36, pp. 1200-1206, 2016.

[5] Y. Che, W. Li, X. Li, J. Zhou, S. Li, and X. Xi, “An improved coordinated control strategy for PV system integration with VSC-MVDC technology," Energies, vol. 10, no. 10, p. 1670, 2017.

[6] N. Jayasekara, P. Wolfs, and M. A. S. Masoum, “An optimal management strategy for distributed storages in distribution networks with high penetrations of PV," Electric Power Systems Research, vol. 116, pp. 147-157, 2014.

[7] W. Zhang, Z. Liu, and L. Shen, "Flexible grid-connection of photovoltaic power generation system with energy storage system for fluctuation smoothing," Electric PowerAutomationEquipment, vol. 33, no. 5, article 106G111, 2013.

[8] Q. Li and J. Zhang, "Solutions of voltage beyond limits in distribution network with distributed photovoltaic generators," Automation of Electric Power Systems, vol. 39, no. 22, pp. 117-123, 2015.

[9] N. Mahdavi, J. H. Braslavsky, M. M. Seron, and S. R. West, "Model predictive control of distributed air-conditioning loads to compensate fluctuations in solar power," IEEE Transactions on Smart Grid, vol. 8, no. 6, pp. 3055-3065, 2017.

[10] D. Yang, X. Zhang, and B. Zhou, "Modeling and control of air conditioning loads for consuming distributed energy sources," Energies, vol. 10, no. 10, p. 1630, 2017.

[11] X. Xu, G. Huang, H. Liu, L. Chen, and Q. Liu, "The study of the dynamic load forecasting model about air-conditioning system based on the terminal user load," Energy and Buildings, vol. 94, pp. 263-268, 2015.

[12] K. Ma, C. Yuan, J. Yang, Z. Liu, and X. Guan, "Switched control strategies of aggregated commercial HVAC systems for demand response in smart grids," Energies, vol. 10, no. 7, p. 953, 2017.

[13] Y. Yao and P. Zhang, "Transactive control of air conditioning loads for mitigating microgrid tie-line power fluctuations," in 
2017 IEEE Power \& Energy Society General Meeting, pp. 1-5, Chicago, IL, USA, July 2017.

[14] N. Lu, "An evaluation of the HVAC load potential for providing load balancing service," IEEE Transactions on Smart Grid, vol. 3, no. 3, pp. 1263-1270, 2012.

[15] G. Ma, G. Xu, R. Ju, and T. Wu, "Study on optimal configuration of the grid-connected wind-solar-battery hybrid power system," International Journal of Sustainable Energy, vol. 36, no. 7, pp. 668-681, 2017.

[16] X. Xu, Y. Huang, C. Liu, W. Wang, and Y. L. Wang, "Influence of distributed photovoltaic generation on voltage in distribution network and solution of voltage beyond limits," Power System Technology, vol. 10, no. 34, pp. 140-146, 2010. 

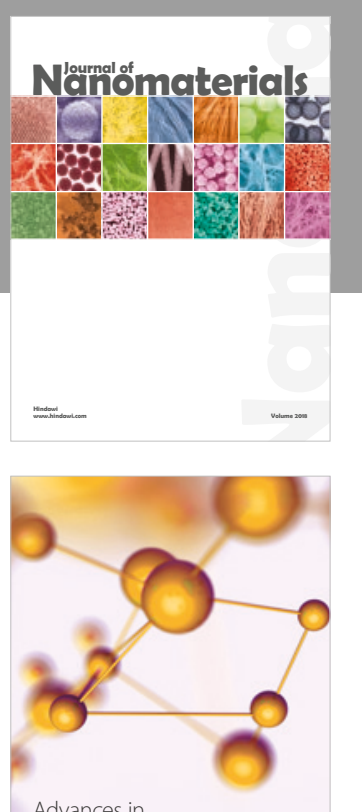

Physical Chemistry
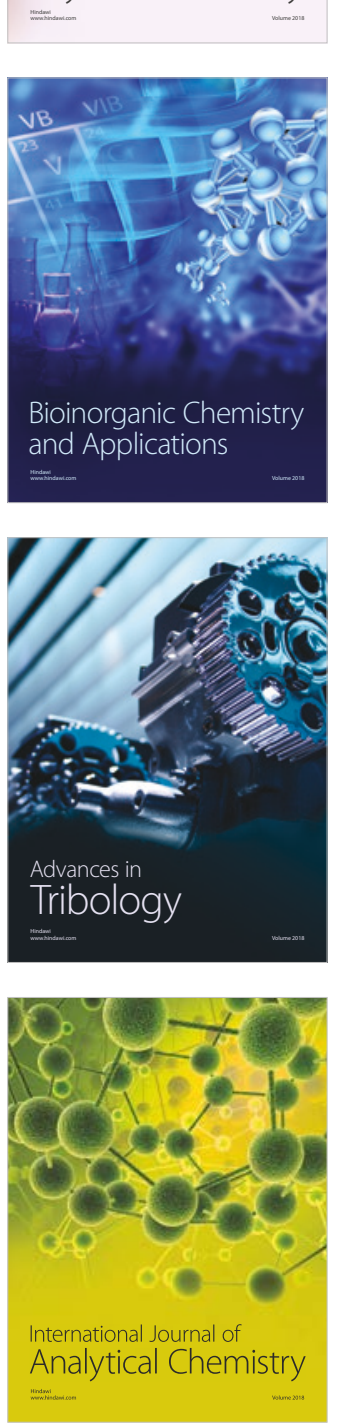

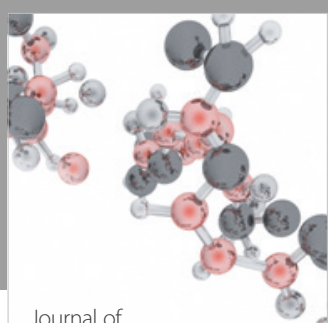

Analytical Methods

in Chemistry

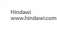

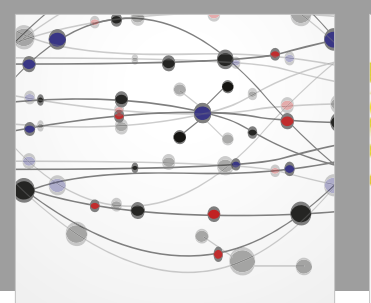

The Scientific World Journal

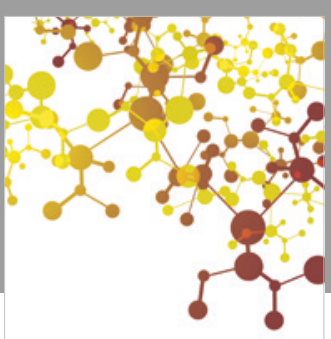

Journal of

Applied Chemistry
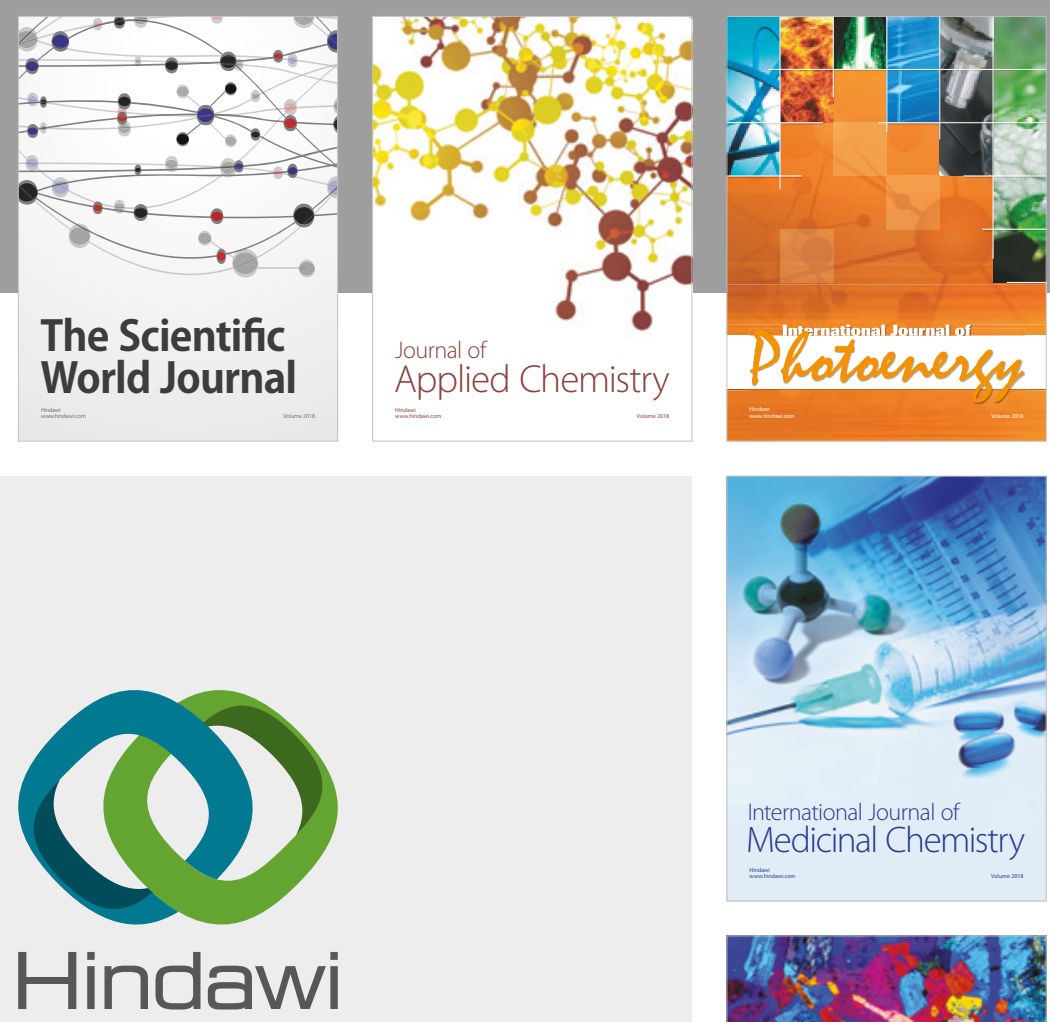

Submit your manuscripts at

www.hindawi.com
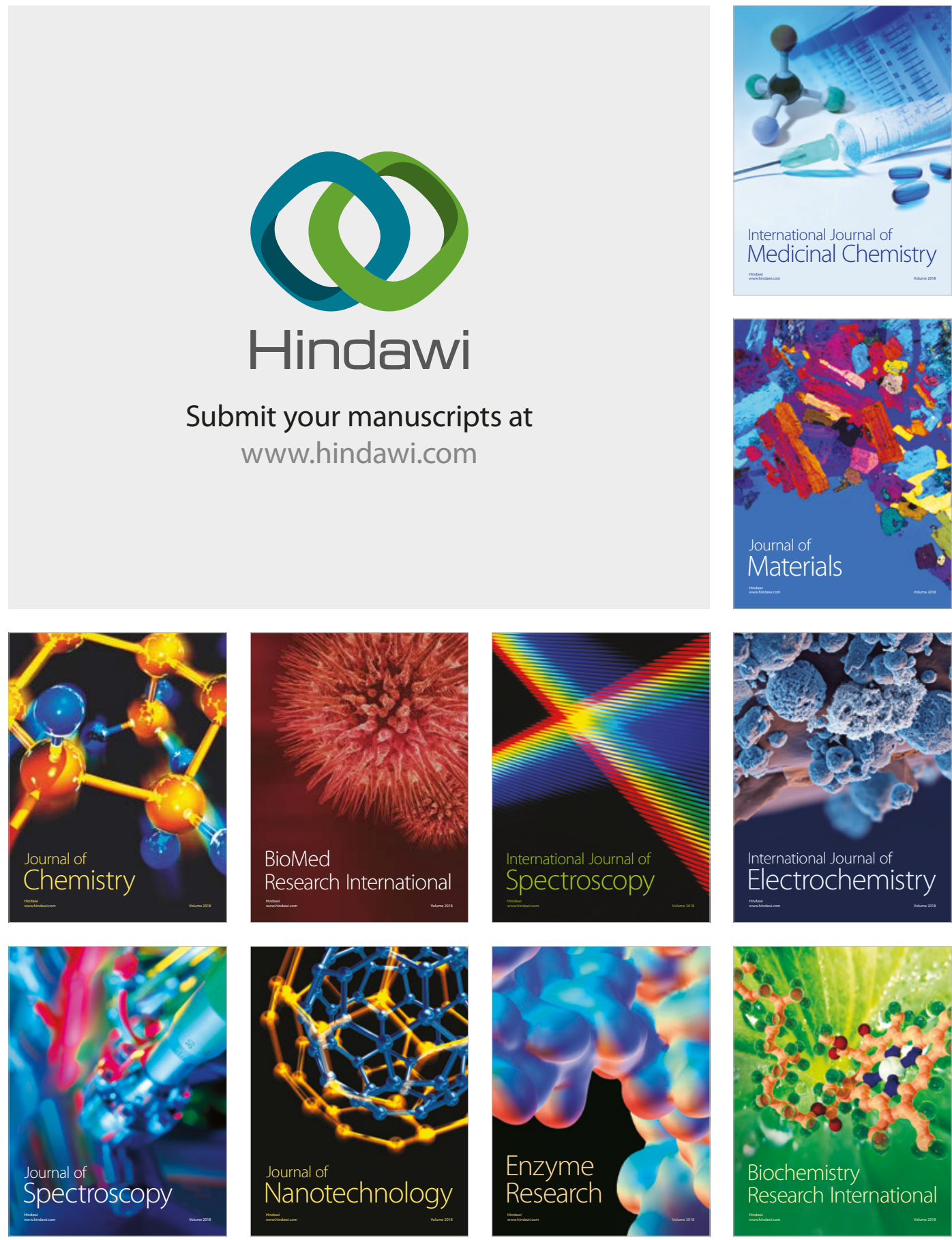
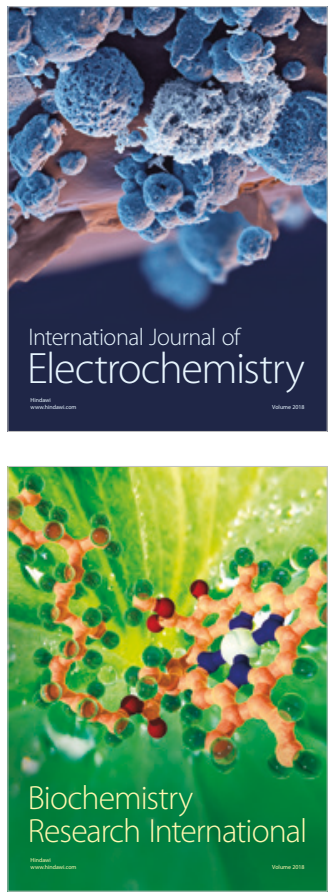